\title{
RELATIONSHIP OF INHERITANCE OF A HIGH PALMITIC MUTATION AND PLANT HEIGHT IN SUNFLOWER
}

\author{
Demurin, Y. ${ }^{*}$, Borisenko, O. and Bochkarev, N.
}

All Russia Research Institute of Oil Crops (VNIIMK), 350038 Filatova 17, Krasnodar, Russia

Received: April 12, 2010

Accepted: August 10, 2010

\section{SUMMARY}

Pleiotropic effect of a high pamitic $(p)$ and high oleic $(O l)$ mutations in sunflower seed oil was investigated in VK580 near-isogenic lines in field conditions. It was found that the $p$ mutation decreased plant height by $41 \mathrm{~cm} \mathrm{(32 \% ),}$ number of leaves by 4 (14\%) and the period of emergence-flowering by 2 days (4\%). The $\mathrm{Ol}$ mutation significantly increased plant height by $4 \mathrm{~cm} \mathrm{(3 \% ).}$

In addition, relationship between inheritance of high palmitic mutation and plant height in the case of selfing of $\mathrm{F}_{2}$ plants was observed in the cross VK850 $(p) \times$ VK508 $(O l)$. The correlation coefficient was $\mathrm{r}=-0.54$ with linear equation $\mathrm{y}=154.49-1.95 \mathrm{x}$. The average plant height of the high palmitic homozygotes in the segregated $\mathrm{F}_{2}$ population was lower and estimated at 109 $\mathrm{cm}$ as compared with $138 \mathrm{~cm}$ in the other plants $\left(\mathrm{LSD}_{05}=3 \mathrm{~cm}\right)$. Thus, a negative effect of the high palmitic mutation on plant height was proved beyond doubt. A question remains whether this phenomenon relates to a gene linkage or true pleiotropy.

Key words: near-isogenic lines, sunflower, fatty acid, mutations

\section{INTRODUCTION}

Effect of sunflower mutants deviating in the fatty acid composition of seed oil on agronomic characters has been studied in several research programs.

The most important paper on this problem was dedicated to the performance of near-isogenic, high and low oleic hybrids of sunflower (Fernandez-Martinez et al., 1993). The isogenic counterparts of four inbred lines, RHA271, RHA274, HA89 and HAJ 152, showed no influence of the $O l$ mutation obtained by Soldatov (1976) on plant height, number of leaves, head diameter, days to flowering, self-compatibility and oil content in seeds. On the other hand, the $\mathrm{Ol}$ mutation had positive effects on seed yield, oil content and above-ground biomass and negative effects on the days to

* Corresponding author: e-mail: yakdemurin@yandex.ru 
flowering, self-compatibility and seed germination. Agronomic trait $\times$ genetic background interaction was also observed (Fernandez-Martinez et al., 1993).

A high palmitic mutation of the line $275 \mathrm{HP}$ was obtained for the first time after $\gamma$-ray treatment of seeds of the OP variety Zarya (Ivanov et al., 1988). No influence on other traits was reported for this mutation. The same observation was done with the high palmitic mutation of the line CAS-5 after seed irradiation with X-rays (Mancha et al., 1994; Osorio et al., 1995). Conversely, another high palmitic mutant, P20 , obtained by chemical mutagenesis after treatment of the seeds with ethylmethanesulfonate (EMS), failed to germinate in the $\mathrm{M}_{3}$ generation indicating the existence of a lethal factor in the homozygote (Mancha et al., 1994). In addition, a new high palmitic mutation was induced in sunflower using nitrosoethylurea (NEU) within a mutagenesis breeding program (Kyrychenko, 2002).

The inheritance of the high palmitic mutation in CAS- 5 was controlled by one or three genes depending on the parents involved in the crosses (Perez-Vich et al., 1999).

In the genetic research conducted at VNIIMK, Russia, the high palmitic genotypes failed to propagate three times. That happened in the $\mathrm{M}_{3}$ generation, after treatment of the seeds of the OP variety Yubileiny 60 with NEU, in $\mathrm{I}_{2}$ of $\mathrm{K} 2222$ and $\mathrm{I}_{1}$ of $\mathrm{N}^{\mathrm{O}} 429934$ accessions in the VIR collection. Later, an inbred line of sunflower, LG30, with high level of palmitic acid in seed oil was developed when screening within a set of cms-lines from Ukrainian germplasm followed by crossing and selfing (Demurin, 2003; Efimenko et al., 2005).

The present research has focused on the influence of both the high oleic and the high palmitic mutations of VNIIMK genetic collection on several morphological characters of the sunflower plants.

\section{MATERIALS AND METHODS}

The VK580 near-isogenic lines from the genetic collection of VNIIMK were involved in the research. VK580 is a normal restorer line. VK508 possesses a high oleic mutation (87\%), VK850 a high palmitic mutation (24\%) and VK805 a-double high oleic $(65 \%)$ and a high palmitic $(20 \%)$ mutations. The high palmitic mutation draws origin from the inbred line LG30.

Plants were grown and self-pollinated in an experiment field of VNIIMK, Krasnodar, in summers of $2007-2009$, at the $70 \times 35 \mathrm{~cm}$ population density. Seed emergence in field conditions of both high palmitic isogenic counterparts, VK850 and VK805, were quite low. At the V6 stage, plants were thinned to get optimum population density. Crossings were made following hand-emasculation.

Fatty acid composition of seed oil was determined by gas chromatography. 


\section{RESULTS AND DISCUSSION}

Pleiotropic effect of the high pamitic $(p)$ and high oleic $(O l)$ mutations in sunflower seed oil was observed in near-isogenic lines derived from VK580 genetic base. The observations were done under field conditions during three years (Table 1). It was found that the $p$ mutation decreased plant height by $41 \mathrm{~cm} \mathrm{(32 \% ),}$ number of leaves by 4 (14\%) and the period of emergence-flowering by 2 days (4\%). The $\mathrm{Ol}$ mutation only caused a significant increase in plant height, by $4 \mathrm{~cm} \mathrm{(3 \% ).}$

Table 1: Mean values and differences from standard genotype (st) of morphometric traits of sunflower isolines across three years.

\begin{tabular}{lcccccc}
\hline Genotype & \multicolumn{2}{c}{ Plant height, cm } & \multicolumn{2}{c}{ Period emergence-flowering, days } & \multicolumn{2}{c}{ Number of leaves } \\
\cline { 2 - 7 } & mean & \pm st & mean & \pm st & mean & \pm st \\
\hline VK580 (st) & 127 & 0 & 54 & 0 & 28 & 0 \\
VK508 OI & 131 & $+4^{*}$ & 54 & 0 & 29 & +1 \\
VK850 $p$ & 86 & $-41^{*}$ & 56 & $+2^{\star}$ & 24 & $-4^{*}$ \\
VK805 OI, $p$ & 89 & $-38^{*}$ & 55 & $+1^{*}$ & 26 & $-2^{*}$ \\
\hline
\end{tabular}

* - significant difference, $p<0.05$

The high palmitic and oleic mutations were found to considerably influence plant height, their joint effect being responsible for $46 \%$ of the total trait variability (Table 2). Moreover, the influences of all factors, including genotype, year, and the genotype $\times$ year interaction, were significant for all characters. The factor of year affected the period of emergence-flowering and the number of leaves by 83 and $73 \%$, respectively.

Table 2: Influence of the studied factors on the analysis of variance for the morphometric traits of VK580 isolines for three years.

\begin{tabular}{lccc}
\hline Factor & Plant height & Period emergence-flowering & Number of leaves \\
\hline Genotype & 0.46 & 0.07 & 0.11 \\
Year & 0.43 & 0.83 & 0.73 \\
Genotype $\times$ year & 0.03 & 0.02 & 0.06 \\
Error & 0.08 & 0.08 & 0.10 \\
\hline
\end{tabular}

In order to verify the negative effect of the high palmitic mutation on the plant height in the isolines, inheritance analysis was carried out (Figure 1).

The $F_{1}$ seed in the cross of two counterparts, VK508 $\times$ VK850, showed a normal low palmitic acid content to be a partial dominant trait with the dominance degree $d=-0,4$. The mean palmitic content values in the parents were 3 and $21 \%$, respectively, whereas the $\mathrm{F}_{1}$ seed showed the value of $9 \%$.

The analysis of individual $\mathrm{F}_{2}$ seeds indicated that the palmitic acid content clearly segregated in two phenotypic classes: the normal low and intermediate levels taken together (4-10\%) and high palmitic level (17-19\%). The distribution of 36:4 in the $\mathrm{F}_{2}$ seeds fitted the ratio of $15: 1$, favoring the hypothesis that the high palmitic 
mutation was controled by two recessive genes $\left(\chi^{2}{ }_{15: 1}=0.96, p>0.05\right)$. A portion of the $\mathrm{F}_{2}$ seed was used to grow $\mathrm{F}_{2}$ plants which were selfed to produce $\mathrm{F}_{3}$ seeds.

The $F_{3}$ seed bulk from $F_{2}$ heads were expected to segregate in two phenotypic classes: the normal low and intermediate level taken together (4-17\%) and high palmitic level (18-23\%). The 173:15 distribution of the palmitic acid content in the $\mathrm{F}_{2}$ heads also fitted the ratio of 15:1 $\left(\chi^{2}{ }_{15: 1}=0.96, \mathrm{p}>0.05\right)$.
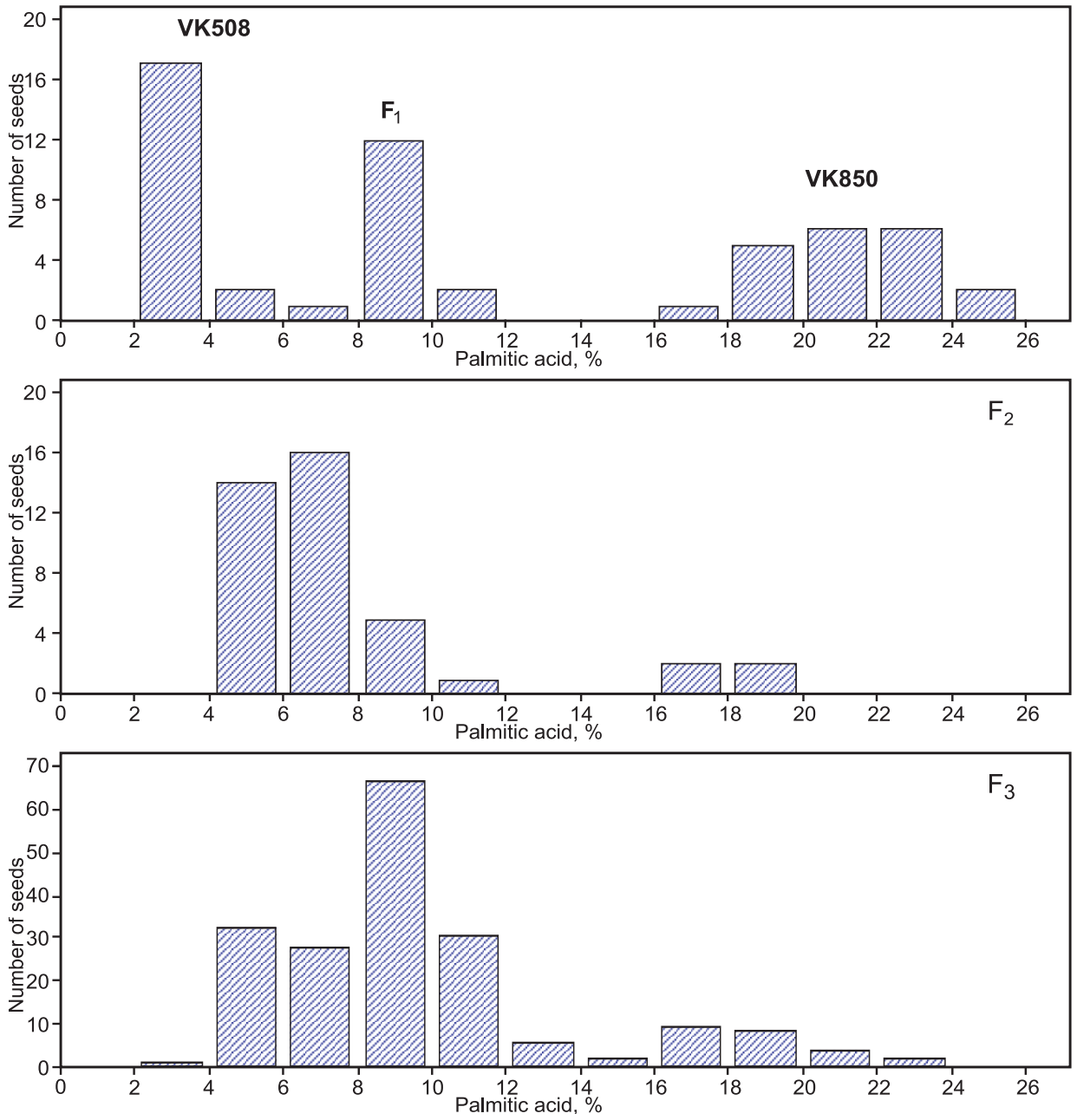

Figure 1: Frequency distributions of palmitic acid content in individual seeds of parents, $F_{1}, F_{2}$ and $F_{3}$ seed bulk (selfed heads of $F_{2}$ plants)

A relationship was observed between the inheritance of high palmitic mutation and plant height when selfing $\mathrm{F}_{2}$ plants of the cross VK850 $\times$ VK508. The correlation coefficient between these traits was $r=-0.54$ with linear regression equation $y=154.49-1.95 x$. An average plant height of the high palmitic homozygotes (15 
plants) in the segregated $\mathrm{F}_{2}$ population was estimated at $109 \mathrm{~cm}$, which was significantly below the $138 \mathrm{~cm}$ for the other 173 plants $\left(\operatorname{LSD}_{05}=3 \mathrm{~cm}\right)$. The difference between the two heights of $\mathrm{F}_{2}$ plants, which amounted to $29 \mathrm{~cm}$, corresponded to the height differences among the parents.

\section{CONCLUSIONS}

The negative effect of the high palmitic mutation on plant height was proved beyond doubt with both near-isogenic lines and by the inheritance analysis. The question remains whether this phenomenon relates to a gene linkage or true pleiotropy. In the case of co-segregation, it should be clarified which gene that controls the palmitic acid content is linked with genes that control plant height.

\section{ACKNOWLEDGEMENTS}

This work was supported by grant 09-04-96588 from the Russian Foundation for Basic Research (RFFI).

\section{REFERENCES}

Demurin, Ya., 2003. Up-to-date results on biochemical genetics of sunflower in VNIIMK. Helia 26(38): 137-141.

Efimenko, S.G., Efimenko, S.K. and Demurin, Y.N., 2005. Development of sunflower line LG30 with increased level of palmitic acid in the seed oil. Scientific Bulletin of VNIIMK, Krasnodar, Russia. 1(132): 14-18.

Fernandez-Martinez, J., Munoz, J. and Gomez-Arnau, J., 1993. Performance of near-isogenic high and low oleic acid hybrids of sunflower. Crop Sci. 33(6): 1158-1163.

Ivanov, P., Petakov, D., Nikolova, V. and Pentchev, E., 1988. Sunflower breeding for high palmitic acid content in the oil. In: Proc $12^{\text {th }}$ Intl. Sunflower Conf., Novi Sad, Yugoslavia, 25-29 July 1988. Intl. Sunflower Assoc., Paris, France 1: 463-465.

Kyrychenko, V.V., 2002. Theoretical basing of sunflower breeding for practical using of heterosis effect, Manuscript of thesis for doctor of agriculture science, Seed Plant Institute UAAS, Dnepropetrovsk, Ukraine, pp.1-32.

Mancha, M., Osorio, J., Garces, R., Ruso, J., Munoz, J. and Fernandez-Martinez, J.M., 1994. New sunflower mutants with altered seed fatty acid composition. Prog. Lipid Res. 33(1) 2): 147-154.

Osorio, J., Fernandez-Martinez, J., Mancha, M., Garces, R., 1995. Mutant sunflowers with high concentration of saturated fatty acids in the oil. Crop Science 35: 739-742.

Perez-Vich, B., Fernandez, J., Garces, R. and Fernandez-Martinez, J.M., 1999. Inheritance of high palmitic acid content in the seed oil of sunflower mutant CAS-5. Theor. Appl. Genet. 98: 496-501.

Soldatov, K.I., 1976. Chemical mutagenesis in sunflower breeding. In: Proc. $7^{\text {th }}$ Intl. Sunflower Conf., Krasnodar, Russia, 27 June-3 July 1976. Intl. Sunflower Assoc., Paris, France 1: 352-357. 
